\title{
Modified two-step extragradient method for solving the pseudomonotone equilibrium programming in a real Hibert space
}

\section{PASAKORN YORDSORN ${ }^{1}$, POOM KUMAM $^{1,2^{*}}$ and HABIB UR REHMAN ${ }^{1}$}

\begin{abstract}
.
The purpose of this paper is to come up with an inertial extragradient method for dealing with a class of pseudomonotone equilibrium problems. This method can be a view as an extension of the paper title "A new twostep proximal algorithm of solving the problem of equilibrium programming" by Lyashko and Semenov et al. (Optimization and Its Applications in Control and Data Sciences: 315-325, 2016). The theorem of weak convergence for solutions of the pseudomonotone equilibrium problems is well-established under standard assumptions placed on cost bifunction in the structure of a real Hilbert spaces. For a numerical experiment, we take up a well-known Nash Cournot equilibrium model of electricity markets to support the well-established convergence results and be adequate to see that our proposed algorithms have a competitive superiority over the time of execution and the number of iterations.
\end{abstract}

Acknowledgments. The authors would like to thank the editor and referee for careful reading, and constructive suggestions that allowed to improve significantly the presentation of this paper.

Funding Information This project was supported by the Theoretical and Computational Science (TaCS) Center under ComputationaL and Applied Science for Smart Innovation Research Cluster (CLASSIC), Faculty of Science, KMUTT. The first author would like to thank the research professional development project under the scholarship of Rajabhat Rajanagarindra University (RRU) for financial support. The third author was was supported by the Petchra Pra Jom Klao Doctoral Scholarship Academic for Ph.D. Program at KMUTT (Grant No. 39/2560).

\section{REFERENCES}

[1] Abubakar, J., Sombut, K. and Ibrahim, A. H., An accelerated subgradient extragradient algorithm for strongly pseudomonotone variational inequality problems, Thai J. Math., 18 (2020), No. 1, 166-187

[2] Alvarez, F. and Attouch, H., An inertial proximal method for maximal monotone operators via discretization of a nonlinear oscillator with damping, Set-Valued Anal., 9 (2001), No. 1-2, 3-11

[3] Bauschke, H. H. Combettes, P. L., Convex analysis and monotone operator theory in Hilbert spaces, Springer, 408 (2011)

[4] Beck, A. and Teboulle, M., A fast iterative shrinkage-thresholding algorithm for linear inverse problems, SIAM J. Imaging Sci., 2 (2009), No. 1 , 183-202

[5] Blum, E., From optimization and variational inequalities to equilibrium problems, Math. Student, 63 (1994), 123-145

Received: 26.09.2019; In revised form: 27.04.2020; Accepted: 04.05.2020

2010 Mathematics Subject Classification. 47J25, 47H05, 47H10, 90C2, 47J25.

Key words and phrases. Extragradient method, inertial methods, equilibrium problem, variational inequality problem, pseudomonotone bifunction, Lipschitz-type condition.

Corresponding author: Poom Kumam; poom.kum@kmutt.ac.th 
[6] Censor, Y., Gibali, A. and Reich, S., The subgradient extragradient method for solving variational inequalities in hilbert space, J. Optim. Theory Appl., 148 (2011), No. 2, 318-335

[7] Cohen, G., Auxiliary problem principle and decomposition of optimization problems, J. Optim. Theory Appl., 32 (1980), No. 3, 277-305

[8] Cohen, G., Auxiliary problem principle extended to variational inequalities, J. Optim. Theory Appl., 59 (1988), No. 2, 325-333

[9] Combettes, P. L. and Hirstoaga, S. A., Equilibrium programming in Hilbert spaces, J. Nonlinear Convex Anal., 6 (2005), No. 1, 117-136

[10] Fan, K., A minimax inequality and applications, Inequalities III (O.Shisha, ed.), Academic Press, New York, 1972

[11] Giannessi, F., Maugeri, A. and Pardalos, P. M., Equilibrium problems: nonsmooth optimization and variational inequality models, Springer Science \& Business Media, 58 (2006)

[12] He, B., A class of projection and contraction methods for monotone variational inequalities, Appl. Math. Optim., 35 (1997), No. 1, 69-76

[13] Hieu, D. V., Muu, L. D. and Anh, P. K., Parallel hybrid extragradient methods for pseudomonotone equilibrium problems and nonexpansive mappings, Numer. Algorithms, 73 (2016), No. 1, 197-217

[14] Konnov, I. V., Application of the proximal point method to nonmonotone equilibrium problems, J. Optim. Theory Appl., 119 (2003), No. 2, 317-333

[15] Korpelevich, G. M., The extragradient method for finding saddle points and other problems, Matecon, 12 (1976), $747-756$

[16] Lyashko, S. I. and Semenov, V. V., A new two-step proximal algorithm of solving the problem of equilibrium programming, Optimization and Its Applications in Control and Data Sciences, Springer, 2016, 315-325

[17] Mastroeni, G., On auxiliary principle for equilibrium problems, Equilibrium problems and variational models, Springer, 2003, 289-298

[18] Minty, G. J., Monotone (nonlinear) operators in Hilbert space, Duke Math. J., 29 (1962), 341-346

[19] Moudafi, A., Proximal point algorithm extended to equilibrium problems, J. Nat. Geom., 15 (1999), No. 1-2, 91-100

[20] Nagurney, A., Network economics-a variational inequality approach 412, Advances in Computational Economics, Kluwer Academic Publishers, 1993

[21] Opial, Z., Weak convergence of the sequence of successive approximations for nonexpansive mappings, Bull. Amer. Math. Soc., 73 (1967), No. 4, 591-597

[22] Polyak, B. T., Some methods of speeding up the convergence of iteration methods, USSR Comput. Math. Math. Phys., 4 (1964), No. 5, 1-17

[23] Popov, L. D., A modification of the arrow-hurwicz method for search of saddle points, Mathematical notes of the Academy of Sciences of the USSR, 28 (1980), No. 5, 845-848

[24] Quoc, T. D., Anh, P. N. and Muu, L. D., Dual extragradient algorithms extended to equilibrium problems, J. Global Optim., 52 (2012), No. 1, 139-159

[25] Quoc, T. D., Dung, M. L. and Nguyen, V. H., Extragradient algorithms extended to equilibrium problems, Optimization, 57 (2008), No. 6, 749-776

[26] Rehman, H., Kumam, P., Cho, Y. J. and Yordsorn, P., Weak convergence of explicit extragradient algorithms for solving equilibirum problems, J. Inequal. Appl., 2019, No. 282, 25 pp.

[27] Rehman, H., Kumam, P. and Dhompongsa, S., Existence of tripled fixed points and solution of functional integral equations through a measure of noncompactness, Carpathian J. Math., 35(2019), No. 2, 193-208

[28] Rockafellar, R. T., Monotone operators and the proximal point algorithm, SIAM J. Control Optim., 14 (1976), No. $5,877-898$

[29] Tiel, J. V., Convex analysis, John Wiley, 1984

[30] Tseng, P., A modified forward-backward splitting method for maximal monotone mappings, SIAM J. Control Optim., 38 (2000), No. 2, 431-446

\author{
${ }^{1}$ Department of MATHEMATics \\ KMUTT-FiXed Point THEORY AND APPLicATIONS ReseARCH Group \\ SCL 802 FiXed POINT LABORATORY, FACULTY OF SCIENCE \\ KING MONGKUT'S UNIVERSITY OF TECHNOLOGY THONBURI (KMUTT), \\ 126 Pracha-Uthit RoAD, BANG MOD, THRUNG KHRU, BANGKOK 10140, THAILAND \\ Email address: ryotarokung@gmail.com \\ Email address: poom. kum@kmutt.ac.th \\ Email address: hrehman.hedegmail.com
}


2 Center of Excellence in Theoretical and Computational SCience (TaCS-CoE), SCIENCE LABORATORY BUILDING, KING MONGKUT'S UNIVERSITY OF TECHNOLOGY THONBURI (KMUTT), 126 Pracha-Uthit RoAD, BAng Mod, Thrung Khru, BANGKOK 10140, Thailand

Email address: poom. kum@kmutt. ac.th 